\title{
Previous and Recent Evidence of Endovascular Therapy in Acute Ischemic Stroke
}

\author{
Dongbeum Song, MD', A-Hyun Cho, MD, PhD²
}

The ideal therapy of acute ischemic stroke is achieved by early recanalization that finally leads to good clinical outcome. The recombinant intravenous tissue plasminogen activator (rtPA) within 4.5 hours was approved as an important thrombolytic treatment. However, the recanalization rate was low in patients with a large artery occlusion. The efficacy of intravenous rtPA regarding recanalization of a large artery occlusion was limited. In several clinical trials, pharmacological and mechanical intra-arterial thrombolytic therapy showed improved recanalization rates, but the favorable outcome had not been achieved. Through those trials and errors, researchers have learned that speed of treatment initiation, patient selection by documentation of large artery occlusion and the use of effective devices could be crucial for good clinical outcomes. Finally, five recent randomized controlled trials of endovascular therapy compared to standard medical care have been published. The superiority of endovascular thrombolysis to standard medical care was proved. In this article, we reviewed previous and recent clinical evidence about endovascular thrombolytic therapy of acute ischemic stroke.

Key Words : Acute ischemic stroke; Thrombolysis; Endovascular therapy

The ideal therapy of acute ischemic stroke is achieved by early reperfusion through recanalization with good clinical outcome. Intravenous recombinant tissue plasminogen activator (IV rtPA) is the only proven therapy for acute ischemic stroke [1].

However, less than $5 \%$ of acute ischemic stroke

'Department of Neurology, Yonsei University College of Medicine, Seoul, ${ }^{2}$ Department of Neurology, The Catholic University of Korea, College of Medicine, Yeouido St. Mary's Hospital, Seoul, Korea Received July 18, 2015;

accepted after revision July 27, 2015.

Correspondence to: A-Hyun Cho, MD, PhD, Department of Neurology, The Catholic University of Korea, College of Medicine, Yeouido St. Mary's Hospital, 63-ro 10, Yeongdungpo-gu, Seoul 150713 Korea.

Tel. 82.2.3779.2433 Fax. 82.2.782.8654

E-mail: ahyun@catholic.ac.kr

This is an Open Access article distributed under the terms of the Creative Commons Attribution Non-Commercial License (http://creativecommons.org/licenses/by-nc/3.0) which permits unrestricted non-commercial use, distribution, and reproduction in any medium, provided the original work is properly cited. patients are eligible for IV rtPA due to a narrow time window and lots of contraindications due to risk of systemic hemorrhage [2]. In addition, the recanalization rate of IV rtPA in large artery occlusion was relatively low (46\%) [3]. Only $14 \%$ of internal carotid artery (ICA) and $55 \%$ of middle cerebral artery (MCA, M1) showed recanalization [3].

Intra-arterial (IA) thrombolytic therapy has favorable risk-benefit ratio due to extended time windows, higher concentrations of fibrinolytic agent delivered to clot, lower systemic exposure to drugs, and higher recanalization rates. However, additional time is required to initiate IA therapy, and it is available only at highly specialized centers. Since the 1990s, randomized controlled trials (RCT) reporting efficacy and safety of IA thrombolysis have been published $[4,5]$. However, IA thrombolysis could not be approved by the FDA because of a lack of evidence. Thereafter, endovascular therapy with mechanical thrombectomy showed a higher recanalization rate, but the clinical efficacy 
about clinical outcome was controversial. In 2013, the three RCTs about the efficacy of endovascular therapy could not show superiority to standard medical care [68]. Through trials and errors, recent new positive clinical trials about endovascular thrombolytic therapy have been reported opening a new endovascular thrombolysis era in acute ischemic stroke [9-14]. In this article, we reviewed past and recent clinical evidence of intraarterial thrombolytic therapy for proper clinical application.

\section{The Past of Intra-Arterial Thrombolysis}

\section{Early days of intra-arterial thrombolysis: PROACT, PROACT II}

Since 1980s, intra-arterial infusion of thrombolytic agents has been performed in patients with acute vertebrobasilar occlusion and carotid territory stroke [15-17]. A randomized phase II trial of recombinant pro-urokinase by direct arterial delivery (PROACT) was published in 1998 [4]. Patients with MCA occlusion within 6 hours from onset were randomized to IA pro-urokinase or placebo. A total of 46 patients were enrolled (intra-arterial group, $\mathrm{n}=26$ ). Recanalization was better in the IA pro-urokinase group $(57.5 \%$ vs. $14.3 \%, 2 \mathrm{P}=0.017)$. However, symptomatic intracerebral hemorrhage $(\mathrm{SICH})$ was more common $(15.4 \%$ vs. $7.1 \%, 2 \mathrm{P}=0.64)$, which is related to intravenous heparin dose. The results showed a possibility of higher recanalization with IA prourokinase. After that, a randomized phase III trial (PROACT II) was published. Eligible patients who are similar to PROACT were randomized to IA prourokinase or placebo. Primary outcome was the modified Rankin scale (mRS) 0, 1, 2 at 3 months. Favorable outcome was better in IA pro-urokinase $(40 \%$ vs. $25 \%, p=0.04)$. Recanalization rate was also better $(66 \%$ vs. $18 \%, p<0.001)$. SICH was more common in IA pro-urokinase $(10 \%$ vs. $2 \%, \mathrm{p}=0.06)$. However, this study was not considered sufficient by FDA. Thereafter, the MELT study, which was performed with a similar design to PROACT II, could not show statistical significance in the primary endpoint and was stopped after IV rtPA approval in Japan [18]. Until recently, intra-arterial thrombolysis has been administered as an off-label therapy within 6 hours in the anterior circulation.

\section{Combined intravenous and intra-arterial thrombol- ysis: EMS, IMS I, IMS II}

The advantages of IV rtPA were speed and availabil- ity, but the recanalization rate is considered lower than intra-arterial therapy. However, the intra-arterial therapy has limitations because of time delay to initiation of treatment. The effectiveness of thrombolysis strongly depends on the time to initiation of therapy. In this context, the concept of combining the advantages of IV rtPA and intraarterial (IA) therapy was firstly explored in a small pilot study. In an EMS study, IV rtPA with IA rtPA was compared to IA rtPA in acute ischemic stroke within 3 hours [19]. The study showed the feasibility and safety of combination of IA plus IV rtPA. Thereafter, a single-arm trial (IMS I) of combination therapy showed better clinical outcome (m RS 0 2, $43 \%$ vs. $28 \%)$ and higher hemorrhage (6.3\% vs. $1.0 \%)$ than NINDS IV rtPA placebo, and similar efficacy and safety to the NINDS tPA group [20]. The time to initiation of intra-arterial therapy was no more than 212 minutes. The IMS II trial is a single-arm trial design similar to IMS I, except that they used an ultrasound micro-infusion system [21]. They also showed a better outcome than NINDS rtPA placebo. Thereafter, a randomized controlled trial (RCT) of combination therapy comparing to IV rtPA got started [6]. Meanwhile, mechanical thrombectomy with use of a device was being explored.

\section{Development of mechanical thrombectomy: MERCI, PENUMBRA}

A first approach to mechanical thrombectomy was the EKOS device, adding low intensity ultrasound to enhance the effect of the lytic agent [20]. EKOS was tested in the IMS II trial. In 2005, the MERCI retrieval system was approved for intracranial thrombectomy. The Merci device is a corkscrew shaped nitinol coil that engages the thrombus. A single-arm trial of mechanical thrombectomy in patients with large vessel occlusion within 8 hours yielded a 57\% recanalization rate. With further IV rtPA, the recanalization rate of the MERCI device could be improved to $69.5 \%$, with $9.8 \%$ of symptomatic bleeding in the Multi-MERCI trial [22].

Penumbra is a second device with a debulking and aspiration technique. In the Penumbra pivotal trial, $81.6 \%$ were recanalized to a thrombolysis in myocardial infarction (TIMI) 2 or 3 in large artery occlusion within 8 hours. SICH rate was as high as $11 \%$. Serious complications such as vasospasm, vessel perforation and reocclusion were reported in $12.8 \%$. Despite a high recanalization rate, the proportion of good clinical outcome at 3 months was only $25 \%$ [23]. 


\section{Endovascular Therapy in Acute Ischemic Stroke}

\section{The advent of stent retriever: SWIFT, TREVO2}

The self-expanding stent retriever was designed to yield rapid flow restoration with less vascular injury. In addition to conventional stenting, the stent promoted thrombectomy by pulling back the deployed stent into the guide catheter. Two RCTs compared efficacy and safety of the new stent retrievers with the FDAapproved predecessor, the MERCI retriever. The SWIFT study, a multicenter RCT recently demonstrated that the Solitaire stent-retriever was superior to MERCI for recanalization without symptomatic hemorrhage ( $61 \%$ vs. $24 \%$, TIMI 2 b/3), clinical outcome (mRS 0 2 at 3 months, 58\% vs. 33\%), and SICH (2\% vs. $11 \%)$ in acute ischemic stroke patients within 8 hours [24]. This study was stopped prematurely due to the higher mortality in the MERCI arm (38\% vs. 17\%). The TREVO2 study also proved the benefit of the Trevo stent retriever over the MERCI device [25]. Thrombolysis in cerebral infarction (TICI) 2, 3 reperfusion was seen in $86 \%$ of the Trevo group and $60 \%$ of the MERCI group. Clinical outcome at 3 months was better in the Trevo group compared to MERCI group (40\% vs. $22 \%$ ). SICH and mortality were similar ( $7 \%$ vs. $9 \%$, $33 \%$ vs. $24 \%$ ). However, trials comparing the next-generation clot retrievers with standard medical therapy were lacking. In 2013, three trials comparing to medical therapy were reported.

\section{Comparison of endovascular therapy with standard medical care: Lessons from the three trials (IMS III, MR RESCUE, SYNTHESIS expansion)}

Three RCTs about endovascular therapy compared to standard medical care are IMS III, MR RESCUE, and SYNTHESIS expansion trial (Table 1). IMS III trial randomized acute ischemic stroke patients who were treated with IV rtPA within 3 hours to additional endovascular therapy or placebo [6]. The trial was stopped early because of futility according to the prespecified rule. The proportion of patients with $\mathrm{mRS}$ 2 or less at 90 days did not differ $(40.8 \%$ vs. $38.7 \%)$. The SICH rate within 30 hours was similar $(6.2 \%$ vs. $5.9 \%)$. In this trial, large artery occlusion was not confirmed in more than half of patients. Time from onset to endovascular treatment was about 249 minutes, which is 37 minutes longer than the IMS I. Among 334 patients who got endovascular therapy, only 5 received

Table 1. Main Clinical Trials of Intra-arterial Thrombolysis before New Era of Endovascular Therapy in Acute Ischemic Stroke

\begin{tabular}{|c|c|c|c|c|}
\hline & PROACT II & IMS III & SYNTHESIS & MR RESCUE \\
\hline Study period & 1996 1998 & 2006 2012 & 2008 2012 & 2004 2011 \\
\hline Subject number & 180 & 656 (early termination) & 362 & 118 \\
\hline Intervention & $\begin{array}{l}\text { IA r-proUK plus heparin } \\
\text { vs. heparin }\end{array}$ & $\begin{array}{l}\text { EVT plus IV rtPA vs } \\
\text { IV rtPA }\end{array}$ & EVT vs. IV rtPA & EVT vs. standard care \\
\hline Used devices & Non applicable & $\begin{array}{l}\text { Merci, Penumbra, EKOS, } \\
\text { Solitaire }\end{array}$ & $\begin{array}{l}\text { Solitaire, Penumbra, } \\
\text { Trevo, Merci }\end{array}$ & Merci, Penumbra \\
\hline Patients included & $\begin{array}{l}\text { Patients with occlusion } \\
\text { of } M C A<6 \mathrm{~h}\end{array}$ & $\begin{array}{l}\text { Patients with IV rtPA } \\
<3 \mathrm{~h}\end{array}$ & $\begin{array}{l}\text { Patients eligible for IV } \\
\text { rtPA }(<4.5 \mathrm{~h}) \text { and EVT } \\
(<6 \mathrm{~h})\end{array}$ & $\begin{array}{l}\text { Patients with LAO } \\
\text { (anterior circulation) } \\
<8 \mathrm{~h}\end{array}$ \\
\hline Imaging at baseline & CT & CT, CT angiography & CT & Multimodal CT/MR \\
\hline Primary endpoint & $\mathrm{mRS} 0,1,2$ & $\mathrm{mRS} 0,1,2$ & $\operatorname{mRS} 0,1,2$ & Shift in $\mathrm{mRS}$ \\
\hline $\begin{array}{l}\text { Time to endovascular } \\
\text { treatment }\end{array}$ & $5.3 \mathrm{~h}$ & $249 \min (122+127)$ & $3.45 \mathrm{~h}$ & $>6 \mathrm{~h}$ \\
\hline Recanalization rate & $66 \%$ (TIMI 2, 3) & $40 \%(\mathrm{TICl} 2 \mathrm{~b} / 3)$ & Not reported & $27 \%(\mathrm{TICl} 2 \mathrm{~b} / 3)$ \\
\hline Clinical outcome & $40 \%$ vs. $25 \%(p=0.04)$ & $40.8 \%$ vs. $38.7 \%$ & $30.4 \%$ vs. $34.8 \%$ & No difference \\
\hline Symptomatic ICH & $10 \%$ vs. $2 \%$ & $6.2 \%$ vs. $5.9 \%$ & $6 \%$ vs. $6 \%$ & $\begin{array}{l}9 \% \text { vs. } 6 \% \\
\text { (penumbral pattern) }\end{array}$ \\
\hline
\end{tabular}

Abbreviations: EVT, endovascular treatment; MCA, middle cerebral artery; LAO, large artery occlusion; mRS, modified Rankin Scale, $\mathrm{ICH}$, intracerebral hemorrhage

Definition of symptomatic ICH; PROACT, ICH with neurological deterioration within 24 hours; IMS III, neurological worsening within 24 hours; SYNTHESIS, SICH within 7 days; MRRESCUE, 4 or more point worsening of NIHSS (associated with a parenchymal hematoma type 2) 
the stent-retriever device. Thus, the recanalization rate was very low (TICI $2 b / 3,38 \%$ for ICA and $44 \%$ for M1). Subgroup analysis of IMS III suggested that there was a benefit for patients treated in shorter time windows. Rapid reperfusion could be crucial for the success of future trials [26]. The SYNTHESIS expansion trial randomized patients within 4.5 hours to endovascular therapy or IV rtPA [7]. The primary outcome $(\mathrm{mRS} 0,1)$ and SICH were not different between the two groups (mRS, $30.4 \%$ vs. $34.8 \%$; SICH $6 \%$ vs. $6 \%$ ). Large artery occlusions were not documented before randomization and $\mathrm{CT}$ angiography (CTA) was not performed. 15 of the 181 patients assigned to endovascular therapy did not receive treatment. In addition, only $14 \%$ used a stent retriever. In this study, the recanalization rate was not reported. The median time to treatment was one hour later in the endovascular group (2.5 hours vs. 3.5 hours). This trial did not reflect modern management of hyperacute large vessel occlusions. MR RESCUE trial (Phase 2b) used multimodal CT or MR in a patient-selection [8]. Patients with large artery occlusion of anterior circulation within 8 hours were randomized to endovascular therapy or standard medical care. Stratification was done according to favorable penumbral patterns or nonpenumbral patterns. There was no interaction between treatment assignment and penumbral pattern. Mean scores of the modified Rankin scale did not differ between endovascular therapy and standard care (3.9 vs. 3.9, $\mathrm{p}=0.99)$. Rate of SICH did not differ across groups. Revascularization (TICI 2a/3) was achieved in $67 \%$ of the patients (endovascular therapy with penumbral pattern). A favorable penumbral pattern did not identify patients who would benefit from endovascular therapy. Endovascular therapy could not show superiority to standard medical care in the MR RESCUE trial. Very slow recruitment over a long time period limited the use of new-technology devices. The time to initiation of endovascular therapy was 370 minutes. The rate of revascularization (TICI $2 \mathrm{~b} / 3$ ) was only $25 \%$ in the endovascular arm.

The lessons of these three studies were that trials of endovascular therapy should confirm patients with severe stroke from large artery occlusion before enrollment, initiate treatment as early as possible, and use new effective thrombectomy devices. Through these trials and errors, researchers were able to publish new recent clinical evidence about the efficacy of endovascular therapy in 2015.

\section{The Recent Update on Endovascular Therapy: 5 Clinical Trials}

Following contemplation regarding reasons why the previous trials mentioned above failed to prove efficacy of endovascular therapy and emergence of novel mechanical thrombectomy devices, new clinical trials were designed and some results of those (MR CLEAN, EXTEND IA, ESCAPE, SWIFT PRIME, REVASCAT) were recently reported [9-11, 13, 14]. Surprisingly, on the contrary to the results of previous trials, those of the recent 5 trials were consistently positive for endovascular therapy in acute ischemic stroke.

All the 5 trials have PROBE design and share common features in that only patients with identifiable occlusive lesions in the anterior circulation on pretreatment imaging (mostly CTA) were included, and the stent retriever technique, including Solitaire, was exclusively or mainly used for endovascular therapy. Although, 3 of 5 trials accepted patients who were outside the IV rtPA time window or contraindicated to IV rtPA, most of the patients enrolled were initially treated with IV rtPA.

Nonetheless, there is some difference in the design of the study, and acknowledging it may be helpful to interpret the results of the trials. The table and the part below will summarize the design and result of these recent trials focusing on the distinct features of each trial (Tables 2, 3).

\section{MR CLEAN}

The MR CLEAN study that was carried out only in the Netherlands was the first study that demonstrated the efficacy of endovascular therapy (EVT), and the result of this study lead to interim analysis of other clinical trials [9]. Acute ischemic stroke patients from proximal artery occlusion in the anterior circulation within 6 hours were assigned either to intra-arterial treatment plus usual care or usual care alone. The primary outcome was mRS at 90 days. The adjusted common odds ratio was 1.67 (95\% confidence interval [CI] 1.21 to 2.3). There were no significant differences in mortality or SICH.

This study is different from the others in several ways. Firstly, this trial is the only trial that completed planned enrollment. It was because patient enrollment of this trial started in December 2010, which was earlier than when halting of IMS III was announced, while the other trials were designed and started enrollment thereafter. Rapid and practically consecutive enrollment that was attributed to the Dutch govern- 


\section{Endovascular Therapy in Acute Ischemic Stroke}

ment's decision not to reimburse endovascular therapy outside of the trial was another reason that this trial could complete its enrollment within a relatively short period of time [12]. Consequently, this study has the largest sample size and planned and post-hoc subgroup analyses could be performed. Noticeably, efficacy of EVT was consistently demonstrated in patients aged 80 or more (odds ratio [OR], 3.24; 95\% CI, 1.22-8.62) and tended to be positive in those with extracranial ICA occlusion (OR, 1.43; 95\% CI, 0.78-2.64). However, the treatment effect of EVT was neutral in the patients with a large infarct core (Alberta Stroke Program Early Computed Tomography Score [ASPECTS]<5; OR, $1.09 ; 95 \% \mathrm{CI}, 0.14-8.46)$ and in those who received

Table 2. Design of the Five Recent Randomized Controlled Trials of Endovascular Therapy in Acute Ischemic Stroke

\begin{tabular}{|c|c|c|c|c|c|}
\hline & MR CLEAN & ESCAPE & EXTEND IA & SWIFT PRIME & RECAVSCAT \\
\hline Design & $\begin{array}{l}\text { Best medical care vs. } \\
\text { Best medical care + } \\
\text { EVT }\end{array}$ & $\begin{array}{l}\text { Best medical care vs. } \\
\text { Best medical care + } \\
\text { EVT }\end{array}$ & $\begin{array}{l}\text { IV rtPA vs. } \\
\text { IV rtPA + EVT }\end{array}$ & $\begin{array}{l}\text { IV rtPA vs. } \\
\text { IV rtPA + EVT }\end{array}$ & $\begin{array}{l}\text { Best medical care vs. } \\
\text { Best medical care + } \\
\text { EVT }\end{array}$ \\
\hline Phase & Phase 3 & Phase 3 & Phase 2 & Phase 3 & Phase 3 \\
\hline Time & $\begin{array}{l}\leq 6 \mathrm{hr} \text {, expected } \\
\text { puncture time }\end{array}$ & $\begin{array}{l}\leq 12 \mathrm{hr} \\
\text { randomization }\end{array}$ & $\begin{array}{l}\leq 6 \mathrm{hr} \text {, expected } \\
\text { puncture time }\end{array}$ & $\begin{array}{l}\leq 6 \mathrm{hr} \text {, expected } \\
\text { puncture time }\end{array}$ & $\begin{array}{l}\leq 8 \mathrm{hr} \text {, expected } \\
\text { puncture time }\end{array}$ \\
\hline EVT modality & $\begin{array}{l}\text { Discretion of } \\
\text { investigator }\end{array}$ & $\begin{array}{l}\text { Recommended } \\
\text { stent retriever }\end{array}$ & $\begin{array}{l}\text { Exclusively } \\
\text { Solitaire FR }\end{array}$ & $\begin{array}{l}\text { Exclusively } \\
\text { Solitaire FR }\end{array}$ & $\begin{array}{l}\text { Exclusively Solitaire } \\
\text { FR }\end{array}$ \\
\hline Primary outcome & 90 days $\mathrm{mRS}$ & 90 days $m R S$ & $\begin{array}{l}\text { - Median percentage } \\
\text { reperfusion at } 24 \mathrm{~h} \\
\text { - NIHSS reduction } \\
\geq 8 \text { points or reaching } \\
0-1 \text { at } 3 \text { days }\end{array}$ & 90 days $\mathrm{mRS}$ & 90 days $\mathrm{mRS}$ \\
\hline Pretreatment Image & NCCT with CTA & NCCT with mCTA & $\begin{array}{l}\text { NCCT with CTA } \\
\text { and CTP }\end{array}$ & $\begin{array}{l}\text { NCCT with CTA } \\
\text { and CTP (or DWI } \\
\text { with MRA and MRP) } \\
\longrightarrow \text { NCCT with CTA } \\
\text { (or DWI with MRA) }\end{array}$ & NCCT with CTA \\
\hline $\begin{array}{l}\text { Image selection } \\
\text { criteria }\end{array}$ & Absent & $\begin{array}{l}\text { Exclusion of large } \\
\text { core } \\
\text { (ASPECTS <6) \& } \\
\text { Exclusion of poor }^{\text {collateral }}{ }^{\text {a }}\end{array}$ & Target mismatch ${ }^{b}$ & $\begin{array}{l}\text { Target mismatch }{ }^{c} \rightarrow \\
\text { Exclusion of large } \\
\text { core } \\
(\text { CT or DWI } \\
\text { ASPECTS <6) }\end{array}$ & $\begin{array}{l}\text { Exclusion of large } \\
\text { core } \\
\text { (CT ASPECTS <7, } \\
\text { DWI ASPECTS <6) }\end{array}$ \\
\hline Premorbid condition & None & Barthel index $>90$ & $m R S \leq 1$ & $m R S \leq 1$ & $m R S \leq 1$ \\
\hline Age & $\geq 18$ & $>18$ & $\geq 18$ & $18-80$ & $18-80$ \\
\hline NIHSS & $\geq 2$ & $\geq 6$ & None & $8-29$ & $\geq 6$ \\
\hline Occlusive lesion & $\begin{array}{l}\text { distal ICA, M1, M2, } \\
\text { A1 }\end{array}$ & $\begin{array}{l}\text { distal ICA, M1, M1 } \\
\text { equivalent }\end{array}$ & ICA, M1, M2 & ICA, M1 & ICA, M1 \\
\hline
\end{tabular}

Abbreviations: IV rtPA, intravenous tissue plasminogen activator; EVT, endovascular therapy; mRS, modified rankin score; NIHSS, National Institute of Health Stroke Scale; NCCT, Noncontrast CT; CTA, CT angiography; mCTA, multiphasic CTA; CTP, CT perfusion; MRP, MR perfusion; DWI, diffusion weighted imaging; MRA, MR angiography; ASPECTS, Alberta Stroke Program Early CT Score; ICA, Internal carotid artery; M1, first segment of middle cerebral artery; M2, second segment of middle cerebral artery

${ }^{a}$ Definition of poor collateral: no or minimal collaterals in a region greater than $50 \%$ of the MCA territory when compared with pial filling on the contralateral side on multiphasic CT angiography

${ }^{\mathrm{b}}$ Definition of target mismatch: Hypoperfused tissue / Core $>1.2$ and Hypoperfusesd tissue - Core $>10 \mathrm{ml}$ and Core $<70 \mathrm{ml}$; Core (rCBF $\leq$ $30 \%)$; Hypoperfused tissue (Tmax $>6 s$ )

'Definition of target mismatch: Hypoperfused tissue / Core $\geq 1.8$ and Hypoperfused tissue - Core $\geq 15 \mathrm{ml}$ and Core $<50 \mathrm{ml}$ and Severely hypoperfused tissue $<100 \mathrm{ml}$; Core (DWI lesion or rCBF $\leq 30 \%$ ); Hypoperfused tissue (Tmax $>6$ s); Severely hypoperfused tissue (Tmax $>10 \mathrm{~s})$ 


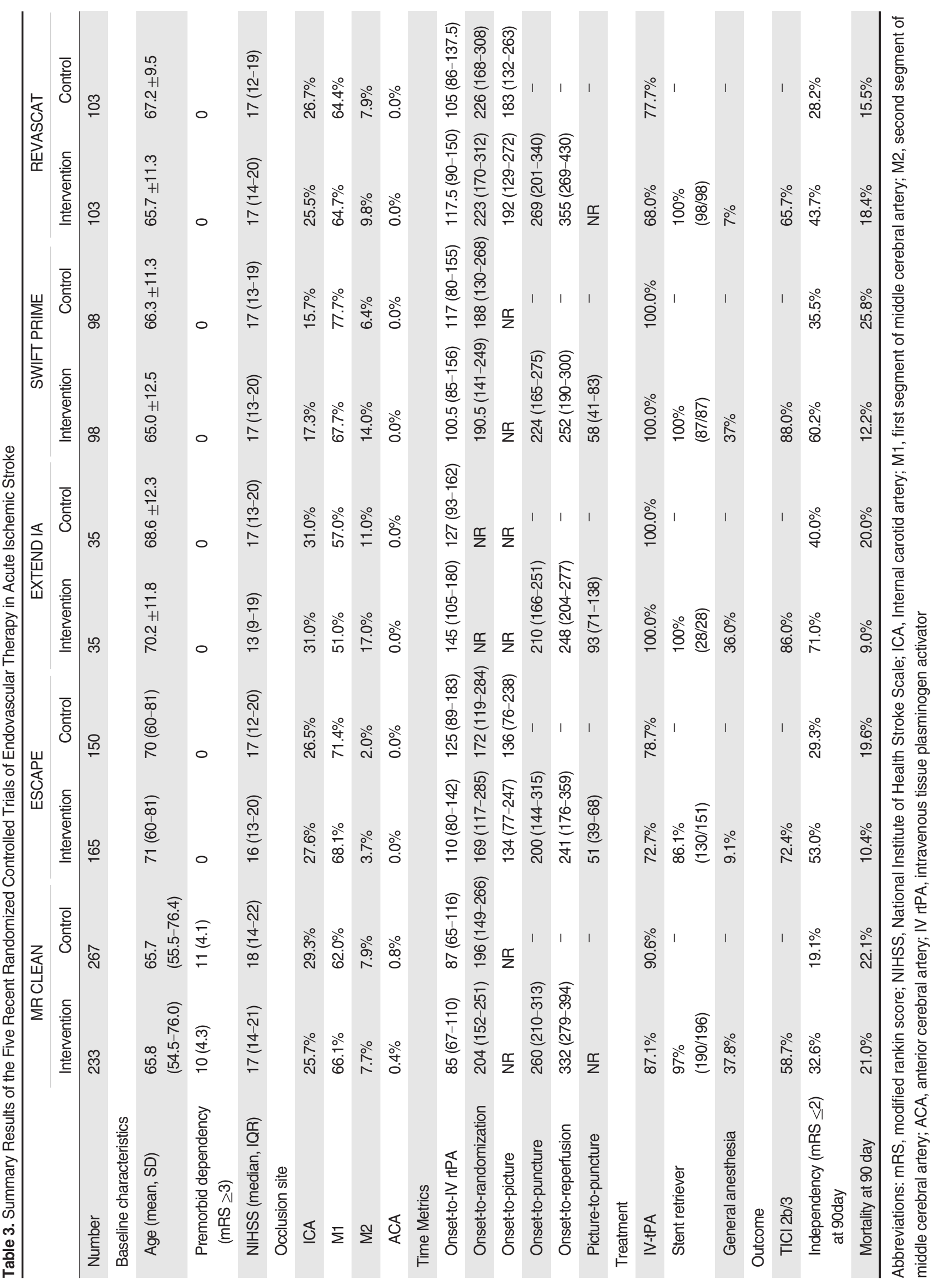




\section{Endovascular Therapy in Acute Ischemic Stroke}

EVT under general anesthesia (OR, 1.09; 95\% CI, $0.69-1.71$ ) [27]. Secondly, the trial has a pragmatic design [28]. It implies broad inclusion criteria, but it rendered study physicians to decide whether to randomize potential candidates. Only $5.6 \%$ of the participants had an extensive infarct core (ASPECTS $<5$ ) at baseline, which may suggest that some potential candidates were actually excluded by this pragmatic design $[29,30]$. However, detailed information of those patients such as the number, characteristics, and outcomes of them were not known. Lastly, the patients who received IV rtPA, accounting for around $90 \%$ of the study population, were randomized only when the clinical response to IV rtPA was insufficient. It may attribute to the finding that the median onset to randomization was as late as of 260 minutes despite median onset to IV rtPA of only 85 minutes. This time delay in workflow the was regarded as one of the main reasons that size of efficacy of MR CLEAN was not as remarkable as that of the other studies.

\section{ESCAPE}

ESCAPE was an international study, which was performed in Canada, the USA, the UK, Ireland and South Korea [11]. Patients with a proximal anterior circulation occlusion were included up to 12 hours after symptom onset. Patients with a large infarct core or poor collateral circulation were excluded. The primary outcome was $\mathrm{mRS}$ at 90 days. The primary outcome favored intervention (OR, 2.6; 95\% CI, 1.7 to 3.8). SICH occurred in $3.6 \%$ of the intervention group and $2.7 \%$ of the control group $(\mathrm{p}=0.75)$.

Notably, this study had the widest time window. Instead of extending the time window, the investigators excluded not only patients with a large infarct core using ASPECTS but also those with poor collateral status assessed with multiphasic CTA. Assessment of collateral status might also be helpful to improve accuracy of the ASPECTS measurement. In contrast to $25 \%$ of the discrepancy between the central and the local sites regarding ASPECTS adjudication in the REVASCAT, which did not assess collateral status, ESCAPE reported only $3.6 \%$ of discrepancy.

ESCAPE emphasized the efficient in-hospital workflow to reduce time to reperfusion with the specific time target (CT to groin puncture within 60 minutes, CT to first recanalization within 90 minutes) and quality improvement program. Furthermore, even in case of IV rtPA, CTA was performed initially and EVT was combined if there was a proximal artery occlusion on CTA without waiting for the response of
IV rtPA. Consequently, this study could achieve the shortest time interval between hospital arrival and reperfusion. It is of interest that this study had demonstrated marked benefit of EVT not only in the improvement of functional outcome, but also in the reduction of mortality. Like MR CLEAN, beneficial effect of EVT was consistent in patients aged 80 or more and patients with extracranial ICA occlusion.

\section{EXTEND IA}

EXTEND IA, which was performed in Australia and New Zealand, was the only phase II study among the 5 trials and thus had the smallest sample size [10].

Acute ischemic stroke patients who were receiving IV rtPA within 4.5 hours were randomized to undergo endovascular therapy with Solitaire or to continue receiving IV rtPA alone. All the patients had occlusion of the internal carotid or middle cerebral artery and evidence of salvageable brain tissue and small ischemic core. The primary outcome was reperfusion at 24 hours and early neurologic improvement. Reperfusion was greater (median, $100 \%$ vs. $37 \%$, p $<0.001$ ) and early neurologic improvement at 3 days ( $80 \%$ vs. $37 \%$, $\mathrm{p}=0.002$ ) was increased in the EVT group. There were no significant differences in rates of death or SICH.

This study demonstrated the highest percentage of patients who achieved independent outcome at 3 months after stroke in the EVT arm (mRS 0 2, 71\% vs. $40 \%, p=0.01$ ). This result might be accounted for the most delicate imaging criteria using a perfusion CT scan. The prior concerns regarding CT perfusion including different processing methods, and time delay for processing were solved with an automated program, (RAPID, noncommercial research version, Stanford University). This study enrolled only patients treated with IV rtPA, but did not delay EVT to check clinical response to IV rtPA, and it lead to a short time interval compared to MR CLEAN or REVASCAT.

\section{SWIFT PRIME}

SWIFT PRIME was the only sponsor-initiated trial funded by Coviden, and it was performed in the USA, Canada and European countries [14]. In this study, only patients treated with IV rtPA were included within 6 hours. Patients had confirmed proximal anterior intracranial occlusion and absence of large ischemiccore. The rate of functional independence (mRS 0 2) was higher in the intervention group $(60 \%$ vs. $35 \%$, $\mathrm{p}<0.001)$. There was no difference in SICH ( $0 \%$ vs. $3 \%, \mathrm{p}=0.12$ ). This trial initially designed to select patients with perfusion imaging analyzed by RAPID 
like EXTEND IA. However, after enrollment of the first 71 patients, the imaging selection paradigm was changed to the exclusion of large core assessed with ASPECTS similar with ESCAPE or REVASCAT in order to accommodate sites with limited perfusion imaging capability and ensure accelerated treatment delivery. The results of SWIFT PRIME were comparable to those of EXTEND IA and ESCAPE.

\section{REVASCAT}

REVASCAT is performed in the single European country, Spain [13]. Acute ischemic stroke patients with confirmed proximal anterior circulation occlusion, without the absence of a large infarct and who could be treated within 8 hours, were randomized to receive either medical and EVT with Solitaire or medical therapy alone. The primary outcome was the severity of global disability at 90 days (mRS). Thrombectomy reduced the severity of disability (adjusted OR 1.7; $95 \%$ CI, 1.05 to 2.8 ). The rates of SICH were $1.9 \%$ in both groups.

The most distinct feature of this study is that it showed the number of potentially eligible patients who were treated outside of the trial (3.7\%) during the enrollment period. It was possible because REVASCAT were carried out in only 4 comprehensive stroke centers in the Catalonia region, and all EVT cases of this area have been included in the observational registry named SONIA.

Similar to MR CLEAN study, if IV rtPA was administered, only patients who do not response to IV rtPA were enrolled in REVASCAT. Since vascular imaging to identify an occlusive lesion was performed 30 minutes after IV rtPA, time parameters, including time to randomization, time to puncture and time to reperfusion, were delayed compared to those of EXTEND IA, ESCAPE, or SWIFT PRIME, and this is pointed out as one of the possible reasons for the relatively less pronounced efficacy of this trial.

This study used ASPECTS to exclude patients with a substantial infarct core, but unlike the ESCAPE study, which reported $3.6 \%$ of discrepancy between central lab and local sites regarding ASPECTS $<6$, there was a $25.0 \%$ discrepancy in REVASCAT. The inclusion of patients having a large core is another explanation for the lower efficacy of endovascular therapy in REVASCAT, and this inter-rater disagreement is noteworthy when implicating the result in real clinical practice.

\section{CONCLUSION}

Trials to establish clinical evidence of endovascular therapy have been performed for several decades. Researchers have learned that speed, device and patients selection are important factors for good outcome from previous clinical trials. Recently published trials showed endovascular therapy is an effective treatment in acute ischemic stroke patients with documented occlusion of the proximal anterior circulation. A new standard of care for acute ischemic stroke management was established. However, the role of stroke physician still remains about the appropriate application of clinical evidence in our real clinical practice by seeking optimized workflow.

\section{References}

1. Tissue plasminogen activator for acute ischemic stroke. The National Institute of Neurological Disorders and Stroke rt-PA Stroke Study Group. N Engl J Med 1995;333:1581-1587

2. de Los Rios la Rosa F, Khoury J, Kissela BM, Flaherty ML, Alwell K, Moomaw CJ, et al. Eligibility for Intravenous Recombinant Tissue-Type Plasminogen Activator Within a Population: The Effect of the European Cooperative Acute Stroke Study (ECASS) III trial. Stroke 2012;43:1591-1595

3. Mazighi M, Serfaty JM, Labreuche J, Laissy JP, Meseguer E, Lavallee PC, et al. Comparison of intravenous alteplase with a combined intravenous-endovascular approach in patients with stroke and confirmed arterial occlusion (RECANALISE study): a prospective cohort study. Lancet Neurol 2009;8:802-809

4. del Zoppo GJ, Higashida RT, Furlan AJ, Pessin MS, Rowley HA, Gent M. PROACT: a phase II randomized trial of recombinant pro-urokinase by direct arterial delivery in acute middle cerebral artery stroke. PROACT Investigators. Prolyse in Acute Cerebral Thromboembolism. Stroke 1998;29:4-11

5. Furlan A, Higashida R, Wechsler L, Gent M, Rowley H, Kase C, et al. Intra-arterial prourokinase for acute ischemic stroke. The PROACT II study: a randomized controlled trial. Prolyse in Acute Cerebral Thromboembolism. JAMA 1999;282:2003-2011

6. Broderick JP, Palesch YY, Demchuk AM, Yeatts SD, Khatri P, Hill MD, et al. Endovascular therapy after intravenous t-PA versus t-PA alone for stroke. $N$ Engl J Med 2013;368:893-903

7. Ciccone A, Valvassori L, Nichelatti M, Sgoifo A, Ponzio M, Sterzi R, et al. Endovascular treatment for acute ischemic stroke. N Engl J Med 2013;368:904-913

8. Kidwell CS, Jahan R, Gornbein J, Alger JR, Nenov V, Ajani Z, et al. A trial of imaging selection and endovascular treatment for ischemic stroke. N Engl J Med 2013;368:914-923

9. Berkhemer OA, Fransen PS, Beumer D, van den Berg LA, Lingsma HF, Yoo AJ, et al. A randomized trial of intraarterial treatment for acute ischemic stroke. N Engl J Med 2015;372:11-20

10. Campbell BC, Mitchell PJ, Kleinig TJ, Dewey HM, Churilov L, Yassi N, et al. Endovascular therapy for ischemic stroke with perfusion-imaging selection. N Engl J Med 2015;372:1009-1018 


\section{Endovascular Therapy in Acute Ischemic Stroke}

11. Goyal M, Demchuk AM, Menon BK, Eesa M, Rempel JL, Thornton J, et al. Randomized assessment of rapid endovascular treatment of ischemic stroke. N Engl J Med 2015;372:1019-1030

12. Hacke W. Interventional thrombectomy for major stroke--a step in the right direction. $N$ Engl J Med 2015;372:76-77

13. Jovin TG, Chamorro A, Cobo E, de Miquel MA, Molina CA, Rovira A, et al. Thrombectomy within 8 hours after symptom onset in ischemic stroke. N Engl J Med 2015;372:2296-2306

14. Saver JL, Goyal M, Bonafe A, Diener HC, Levy EI, Pereira VM, et al. Stent-retriever thrombectomy after intravenous t-PA vs. t-PA alone in stroke. $N$ Engl J Med 2015;372: 2285-2295

15. Hacke W, Zeumer H, Ferbert A, Bruckmann H, del Zoppo GJ. Intra-arterial thrombolytic therapy improves outcome in patients with acute vertebrobasilar occlusive disease. Stroke 1988;19:12161222

16. del Zoppo GJ, Ferbert A, Otis S, Bruckmann H, Hacke W, Zyroff $\mathrm{J}$, et al. Local intra-arterial fibrinolytic therapy in acute carotid territory stroke. A pilot study. Stroke 1988;19:307-313

17. Zeumer H, Freitag HJ, Zanella F, Thie A, Arning C. Local intraarterial fibrinolytic therapy in patients with stroke: Urokinase versus recombinant tissue plasminogen activator (r-tPA). Neuroradiology 1993;35:159-162

18. Ogawa A, Mori E, Minematsu K, Taki W, Takahashi A, Nemoto $\mathrm{S}$, et al. Randomized trial of intraarterial infusion of urokinase within 6 hours of middle cerebral artery stroke: the middle cerebral artery embolism local fibrinolytic intervention trial (MELT) Japan. Stroke 2007;38:2633-2639

19. Lewandowski CA, Frankel M, Tomsick TA, Broderick J, Frey J, Clark W, et al. Combined intravenous and intra-arterial r-tPA versus intra-arterial therapy of acute ischemic stroke: Emergency management of stroke (EMS) bridging trial. Stroke 1999;30:25982605

20. Investigators IMS Study. Combined intravenous and intra-arterial recanalization for acute ischemic stroke: the interventional management of stroke study. Stroke 2004;35:904-911

21. Investigators II Trial investigators. The interventional manage- ment of stroke (IMS) II study. Stroke 2007;38:2127-2135

22. Smith WS, Sung G, Saver J, Budzik R, Duckwiler G, Liebeskind DS, et al. Mechanical thrombectomy for acute ischemic stroke: Final results of the Multi MERCI trial. Stroke 2008;39:1205-1212

23. Penumbra Pivotal Stroke Trial Investigators. The penumbra pivotal stroke trial: safety and effectiveness of a new generation of mechanical devices for clot removal in intracranial large vessel occlusive disease. Stroke 2009;40:2761-2768

24. Saver JL, Jahan R, Levy EI, Jovin TG, Baxter B, Nogueira RG, et al. Solitaire flow restoration device versus the Merci Retriever in patients with acute ischaemic stroke (SWIFT): a randomised, parallel-group, non-inferiority trial. Lancet 2012;380:1241-1249

25. Nogueira RG, Lutsep HL, Gupta R, Jovin TG, Albers GW, Walker GA, et al. TREVO versus Merci retrievers for thrombectomy revascularisation of large vessel occlusions in acute ischaemic stroke (TREVO 2): a randomised trial. Lancet 2012;380:1231-1240

26. Khatri P, Yeatts SD, Mazighi M, Broderick JP, Liebeskind DS, Demchuk AM, et al. Time to angiographic reperfusion and clinical outcome after acute ischaemic stroke: an analysis of data from the Interventional Management of Stroke (IMS III) phase 3 trial. Lancet Neurol 2014;13:567-574

27. van den Berg LA, Koelman DL, Berkhemer OA, Rozeman AD, Fransen PS, Beumer D, et al. Type of anesthesia and differences in clinical outcome after intra-arterial treatment for ischemic stroke. Stroke 2015;46:1257-1262

28. Fransen PS, Beumer D, Berkhemer OA, van den Berg LA, Lingsma $\mathrm{H}$, van der Lugt A, et al. MR CLEAN, a multicenter randomized clinical trial of endovascular treatment for acute ischemic stroke in the Netherlands: study protocol for a randomized controlled trial. Trials 2014;15:343

29. Grotta JC, Hacke W. Stroke neurologist's Perspective on the New Endovascular Trials. Stroke 2015;46:1447-1452

30. Menon BK, Campbell BC, Levi C, Goyal M. Role of imaging in current acute ischemic stroke workflow for endovascular therapy. Stroke 2015;46:1453-1461 
Dongbeum Song, et al. 